\title{
SUPERIOR MESENTERIC AND PORTAL VEIN THROMBOSIS WITH HYPERHOMOCYSTEINEMIA
}

Tumma Shalini' ${ }^{1}$ Gaddam Vijay Bhargava ${ }^{2}$, Kota Sreedha Rao ${ }^{3}$, Bhavya Bayana ${ }^{4}$

\section{HOW TO CITE THIS ARTICLE:}

Tumma Shalini, Gaddam Vijay Bhargava, Kota Sreedha Rao, Bhavya Bayana. "Superior Mesenteric and Portal Vein Thrombosis with Hyperhomocysteinemia". Journal of Evolution of Medical and Dental Sciences 2015; Vol. 4, Issue 11, February 05; Page: 1885-1888, DOI: 10.14260/jemds/2015/272

\begin{abstract}
Superior mesenteric venous thrombosis is a rare \& life threatening condition. We report a case of 18 years old boy presented to emergency department with pain abdomen, fever, Melena for almost week duration. Bowel sounds were absent since two days. With a preoperative diagnosis of peritonitis Patient was taken up for emergency laparotomy. Resection of gangrenous small bowel and end to end anastomosis was done. Intra operatively thrombus in SMV was found. Coagulation profile was normal except for elevated homocystine levels. Early postoperative period was stormy. Patient was started on LMV Heparin from day -1. Pregangrenous changes were seen in contrast CT abdomen on Day-4. We managed conservatively with anticoagulation therapy in the postoperative period. Pregangrenous changes disappeared with conservative management. Patient was shifted to oral warfarin and discharged on $3^{\text {rd }}$ week. Follow up Doppler USG abdomen revealed a portal vein of normal size \& caliber with no evidence of thrombus. On postoperative follow up for one year, patient is doing well. Hyperhomocycteinemia is an independent predisposing factor to superior mesenteric venous thrombus.
\end{abstract}

KEYWORDS: SMV thrombosis; small bowel gangrene; homocysteinemia, anticoagulation.

INTRODUCTION: Mesenteric venous thrombosis is a rare and life threatening condition which accounts for less than 1 in 1000 laparotomies for acute abdomen.[1] A case of mesenteric venous thrombosis presenting with bowel infarction with associated hyperhomocystenemia is reported here.

CASE REPORT: An 18-year-old boy, referred from multiple hospitals, presented to our emergency department with complaints of abdominal pain since 10 days, worsening over the past 3 days, 2 episodes of melena and high-grade fever. He was alert and febrile. He had mild pallor and tachycardia. On physical examination, severe abdominal tenderness was present with guarding and absent bowel sounds. No prior history of trauma or any significant medical or surgical history.

X-ray erect abdomen showed multiple air fluid levels (Small bowel pattern). USG abdomen showed decreased peristalsis of bowel loops and filling defect in the portal vein. Contrast CT abdomen showed a thrombus in the superior mesenteric vein (Fig. 1). Thrombus extending up to the right branch of portal vein (Fig. 2). Routine laboratory investigations showed leukocytosis. With a preoperative diagnosis of peritonitis with bowel gangrene, patient was taken up for emergency laparotomy.

At laparotomy, $90 \mathrm{cms}$ of mid small bowel was gangrenous which was about $80 \mathrm{cms}$ from the D-J flexure. Mesentery was edematous; rest of the bowel was normal (Fig. 3). Resection of the gangrenous small bowel \& end-end anastomosis was performed. Patient was started on LMW heparin. Cardiac examination was normal with a normal 2D-Echo. Hypercoagulable workup revealed elevated levels of homocysteine in the blood. Antithrombin III, Lupus anticoagulant, Protein C and Protein S were found to be within normal limits. Lipid profile was normal. 


\section{CASE REPORT}

Patient's condition was stormy in the early postoperative period. He again developed abdominal pain on the $4^{\text {th }}$ postoperative day. Post-operative contrast CT abdomen showed pregangrenous changes with bowel wall thickening and intramural air in the small bowel (Fig. 4). A second laparotomy was debated, but subsequently opined to treat conservatively on anticoagulants, broad-spectrum antibiotics, and parenteral nutrition. He was also supplemented with Vitamin B12, Pyridoxine and Folic acid. The patient gradually settled and recovered well. He was started on oral warfarin and discharged on $18^{\text {th }}$ postoperative day.

Histopathological examination of the resected specimen showed transmural necrosis \& marked congestion. Follow up Doppler USG abdomen revealed a portal vein of normal size \& caliber with no evidence of thrombus.

DISCUSSION: Mesenteric venous thrombosis (also known as visceral venous thrombosis) is a rare but lethal form of mesenteric ischemia. Elliot first described it as a cause of mesenteric ischemia in 1895. It accounts for $10-15 \%$ of all cases of mesenteric ischemia.[2] Various risk factors include hypercoagulable states (eg. polycythemia vera, protein $\mathrm{C}$ and $\mathrm{S}$ deficiencies), visceral infection, portal hypertension, blunt abdominal trauma, malignancy and previous abdominal surgeries.[3] There may be no underlying cause found in $25-50 \%$ of the patients.

Patients' clinical findings depend on the mesenteric veins involved, the extent of thrombosis and the degree of bowel wall ischemia. SMV is most commonly involved with extension of thrombus into the portal vein. IMV is typically spared. ${ }^{4]}$ Bowel infarction ultimately develops in $30 \%$ to $60 \%$ of patients with acute MVT.

Plain abdominal films are often the initial diagnostic test and are generally of little value. Thumb printing may be seen which is indicative of the mucosal edema resulting from venous congestion. CT of the abdomen with intravenous contrast is the diagnostic test of choice for patients with suspected acute MVT, with a reported sensitivity of more than 90\%.[5] Findings include a luminal venous thrombus and other features such as thickening, pneumatosis, or streaking of the mesentery.

Treatment is generally directed at limiting progressive venous thrombosis, reducing the risk for bowel necrosis, and performing timely resection in those with irreversible bowel ischemia.

Our patient presented with features of bowel infarction, hence laparotomy was done. Resection of the gangrenous small bowel \& end-end anastomosis was performed. Although he developed pregangrenous changes postoperatively and second look laparotomy was debated, anticoagulation formed the mainstay with supportive management and parenteral nutrition.[6]

Treatment was also directed towards correction of his underlying hyperhomocysteinemia with folate, B12 and B6 supplementation.

In general hyperhomocysteinemia is known to represent an independent predisposing factor to splanchnic venous thrombosis but almost all the patients so far described in whom portal or mesenteric thrombosis was linked with hyperhomocysteinemia also had at least one additional prothrombotic disorder.[7]

This is the first case being reported in literature with Hyperhomocysteinemia being probably the cause for the SMV thrombosis. Several mechanisms have been suggested as the possible cause of accelerated vascular disease in patients with homocysteinemia which include endothelial cell damage, smooth muscle cell proliferation, lipid peroxidation, upregulation of prothrombotic factors (XII and V), down regulation of antithrombotic factors or endothelial-derived nitric oxide.[8] 


\section{CASE REPORT}

\section{REFERENCES:}

1. Kazmers A: Intestinal ischemia caused by venous thrombosis. In Vascular Surgery. Philadelphia, WB Saunders, 1995.

2. Hugon S., de Clercq P., Landen S., et al: Acute mesenteric vein thrombosis. Ann Emerg Med 2007; 50: 623-624.

3. Abu-Daff S., Abu-Daff N., Al-Shahed M., et al: Mesenteric venous thrombosis and factors associated with mortality: a statistical analysis with five-year follow-up. J Gastrointest Surg 2009; 13: 1245-1250.

4. Grisham A., Lohr J., Guenther J. M., et al: Deciphering mesenteric venous thrombosis: imaging and treatment. Vasc Endovasc Surg 2005; 39: 473-479.

5. Morasch M. D., Ebaugh J. L., Chiou A. C., et al: Mesenteric venous thrombosis: a changing clinical entity. J Vasc Surg 2001; 34: 680-684.

6. Roberts, 2006Roberts A., Baum S., Pencost M. J., et al Thrombolysis: Clinical Applications. Abrams' Angiography Interventional Radiology. Philadelphia: Lippincott Williams \& Wilkins, 2006.

7. Vitamin B12 deficiency, hyperhomocysteinemia and thrombosis: a case and control study. Remacha AF, Souto JC, Piñana JL, Sardà MP, Queraltó JM, Martí-Fabregas J, García-Moll X, Férnandez C, Rodriguez A, Cuesta J - Int. J. Hematol. - Apr 2011; 93(4); 458-645.

8. Eldibany M. M., Caprini J. A.: Hyperhomocysteinemia and thrombosis: an overview. Arch Pathol Lab Med 2007; 131: 872-884.

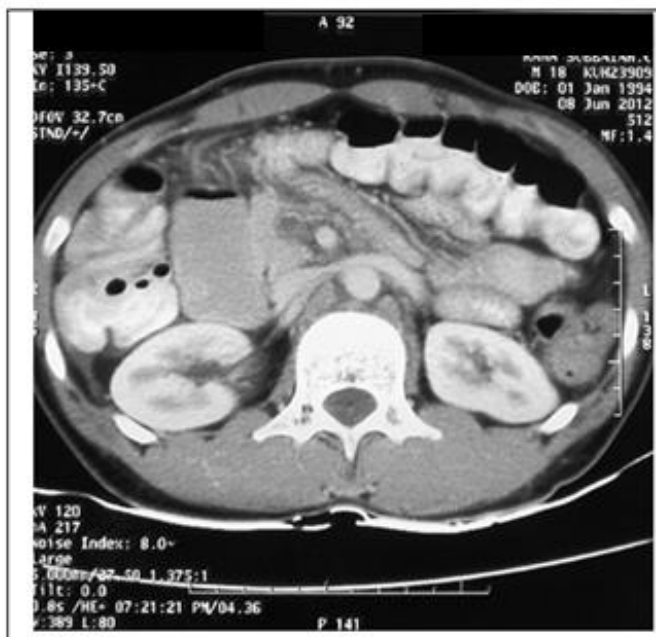

Fig 1: Contrast CT Abdomen showing a large thrombus in the superior mesenteric vein

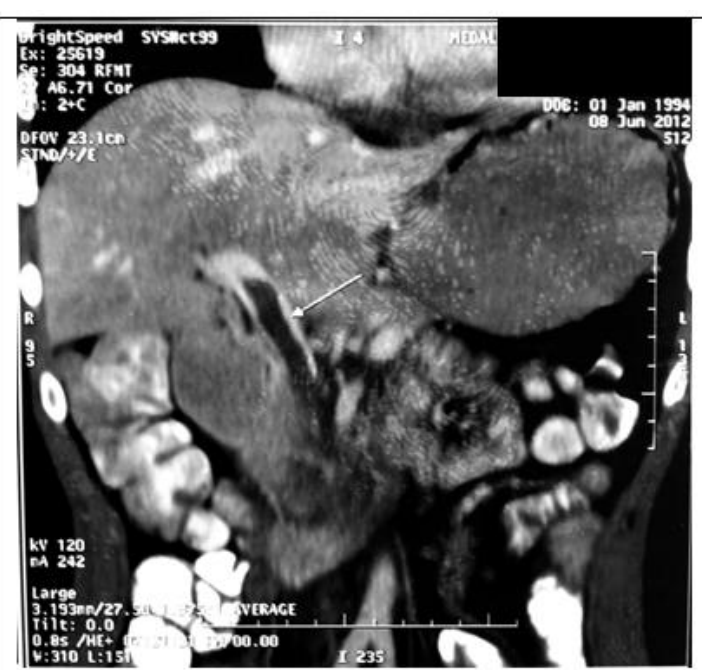

Fig. 2: Contrast CT Abdomen showing a large thrombus (arrow) in the portal vein 


\section{CASE REPORT}

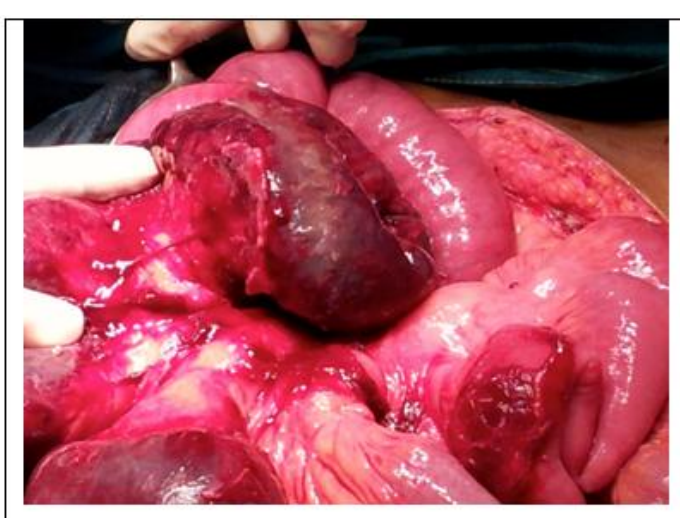

Fig. 3: Intraoperative photograph showing gangrenous small bowel loops.

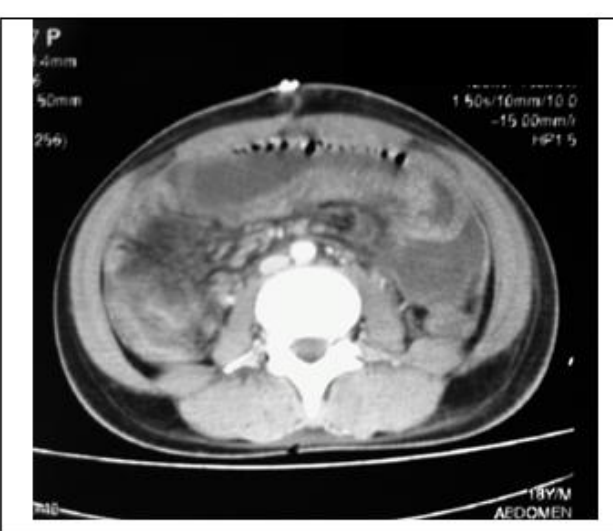

Fig. 4: Postoperative CT abdomen showing pregangrenous changes.

\section{AUTHORS:}

1. Tumma Shalini

2. Gaddam Vijay Bhargava

3. Kota Sreedha Rao

4. Bhavya Bayana

\section{PARTICULARS OF CONTRIBUTORS:}

1. Assistant Professor, Department of General Surgery, Osmania Medical College, Hyderabad.

2. Assistant Professor, Department of General Surgery, Osmania Medical College, Hyderabad.

3. Professor, Department of General Surgery, Osmania Medical College, Hyderabad.
4. Junior Resident, Department of General Surgery, Osmania Medical College, Hyderabad.

\section{NAME ADDRESS EMAIL ID OF THE CORRESPONDING AUTHOR:}

Dr. Tumma Shalini, \# 9-3-15, Katikoni Kunta, Behind Siddartha High School, Chamapet, Hyderabad-500079, Telangana. E-mail: chirusri14@gmail.com

Date of Submission: $12 / 01 / 2015$.

Date of Peer Review: 13/01/2015.

Date of Acceptance: 27/01/2015.

Date of Publishing: 05/02/2015. 